\title{
KAJIAN KOMPARASI ALGORITMA C4.5, NAÏVE BAYES DAN NEURAL NETWORK DALAM PEMILIHAN PENERIMA BEASISWA (Studi Kasus pada SMA Muhammadiyah 4 Jakarta )
}

\author{
Ulfa Pauziah \\ Program Studi Teknik Informatika, Universitas Indraprasta PGRI \\ Email: pelangi_ulfa@yahoo.com
}

\begin{abstract}
ABSTRAK
Salah satu masalah pendidikan saat ini yang dihadapi oleh bangsa Indonesia adalah bagaimana meningkatkan mutu pendidikan disetiap jenjang. Adakalanya memang benar sang pelajar tidak mampu secara finansial, tapi tak jarang dari kalangan mampu pun memanfaatkan surat ini. Yang penting bisa sekolah gratis. Jikalau targetnya adalah sekolah gratis tanpa pertanggungjawabkan " beasiswa" yang diterima, seharusnya lembaga pendidikan mematok beberapa peraturan yang memacu prestasi penerima beasiswa. Oleh karena itu dalam penelitian ini dilakukan komparasi algoritma $\mathrm{C} 4.5$, nä̈ve bayes dan neural network yang diaplikasikan terhadap data siswa yang menerima beasiswa. Penelitian ini bertujuan untuk mengukur tingkat akurasi dari kajian komparasi 3 buah algoritma dalam pemilihan calon penerima beasiswa di SMA Muhammadiyah 4 Jakarta. Dari hasil pengujian dengan mengukur kinerja ketiga algoritma tersebut menggunakan metode pengujian Cross Validation, Confusion Matrix dan Kurva ROC, diketahui bahwa algoritma Nä̈ve Bayes memiliki nilai accuracypaling tinggi, yaitu $86.5672 \%$, diikuti oleh metode $C 4.5$ dengan accuracy sebesar $67.1642 \%$ dan yang terendah adalah metode Neural Network dengan nilai accuracy $82.0896 \%$.
\end{abstract}

Kata Kunci: C4.5, Nä̈ve Bayes, Neural Network.

\section{Pendahuluan}

Pendidikan di Indonesia selalu berhadapan dengan persoalan kemiskinan. Kemiskinan ini kemudian menjadi alasan seseorang mengajukan permohonan beasiswa kepada lembaga pendidikan. Berbagai langkahpun ditempuh, antara lain melalui ketersediaan dana pembebasan biaya sekolah melalui program Surat Keterangan Tidak Mampu (SKTM) yang dikeluarkan dari kantor kecamatan setempat. Agar penerima beasiswa ini terus terpacu meningkatkan prestasi akademisnya, tidak keliru apabila lembaga pendidikan tidak serta merta mengabulkan permohonan beasiswa yang diajukan.

Untuk mengatasi masalah tersebut, maka diuji menggunakan 3 buah metode algoritma yaitu algoritma C4.5, algoritma naïve bayes dan neural network. Dari ketiga buah metode tersebut akan dikaji metode mana yang paling akurat digunakan untuk mengukur tingkat kelayakan para siswa/siswi dalam menerima bantuan beasiswa.

\section{Tinjauan Pustaka}

Beasiswa adalah penghasilan bagi yang menerimanya (Anneahira, 2012). Dalam ketentuan pasal 4 ayat (1) UU $\mathrm{PPh} / 2000$ pengertian penghasilan adalah tambahan kemampuan ekonomis dengan nama dan dalam bentuk apapun yang diterima atau diperoleh dari sumber Indonesia atau luar Indonesia yang dapat digunakan untuk konsumsi atau menambah kekayaan wajib pajak (WP).

Data Mining adalah sebuah proses, yang mana dalam melakukan prosesnya harus sesuai dengan prosedur dari proses tersebut, yaitu CRISP-DM (Cross-Industry Standard Process for Data Mining), yang terdiri dari keseluruhan proses, preprosesing data, pembentukan model, model evaluasi, dan tahap akhir penyebaran model (Larose, 2005). 
Quinlan (1993) mengemukakan bahwa C4.5 adalah algoritma yang digunakan untuk klasifikasi data yang dapat mengolah data/atribut numerik, algoritma ini dapat mengatasi nilai atribut yang hilang, dan dapat mengatasi data kontinyu dan pruning / penyederhanaan.

Algoritma Naive bayes merupakan salah satu metode pengklasifikasi berpeluang sederhana yang berdasarkan pada penerapan Teorema Bayes dengan asumsi antar variabel penjelas saling bebas (independen).

Neural network adalah satu set unit input/output yang terhubung dimana tiap relasinya memiliki bobot. Neural network dimaksudkan untuk mensimulasikan perilaku system biologi susunan syaraf manusia, yang terdiri dari sejumlah besar unit pemroses yang disebut neuron, yang beroperasi secara parallel (Alpayadin, 2010).

Weka (Waikato Environment for Knowledge Analysis) adalah sebuah alat (tool) yang merupakan aplikasi data mining berbasis open source (GPL) yang ditulis dengan Java.

\section{Metodologi Penelitian}

Jenis penelitian ini adalah sebagai berikut:

1. Penelitian Eksperimental

Penelitian eksperimental merupakan penelitian yang bersifat uji coba, memanipulasi dan mempengaruhi hal-hal yang terkait dengan seluruh variabel atau atribut.

2. Penelitian Perbandingan atau studi komparasi yakni dengan membandingkan antara tiga macam algoritma yaitu algoritma C4.5, Naïve Bayes dan Neural Network.

\section{Hasil dan Pembahasan}

Penelitian ini bertujuan untuk menentukan akurasi kelayakan pemberian beasiswa yang dibandingkan dengan menggunakan metode algoritma C4.5, Naïve bayes, dan Neural Network. Setelah itu membandingkan nilai akurasi ketiga metode tersebut, dalam menentukan hasil penelitian ini menggunakan data training berjumlah 234 data dan data testing berjumlah 197 data.

Langkah-langkah untuk membuat algoritma C.45 dengan memakai data training yang berjumlah 197, yaitu:

1. Siapkan data training. Data testing yang digunakan penelitian ini sebanyak 197 data.

2. Hitung nilai entropy

Setelah dilakukan perhitungan entropy dengan menggunakan rumus dibawah ini didapat entropy sebagai berikut:

$$
\begin{aligned}
\operatorname{Entropy}(\delta) & =\sum_{i-1}^{n}-\rho i * \log \log _{2} \rho i \\
& =\left(80 / 197 . \log _{2}(80 / 197)\right)+\left(-117 / 173 . \log _{2}(117 / 197)\right) \\
& =-2.0518
\end{aligned}
$$

3. Setelah itu, hitung nilai gain untuk setiap atribut, lalu pilih nilai gain yang tertinggi. Nilai gain tertinggi itulah yang akan menjadi akar dari pohon. Perhitungan Gain menggunakan rumus dibawah ini. Misalkan untuk atribut kehadiran akan didapat gain sebagai berikut:

$$
\operatorname{Gain}(S, A)=\operatorname{Entropy}(S)-\sum_{i=1}^{n} \frac{|S i|}{S} * \operatorname{Entropy}(S i)
$$

$$
\begin{aligned}
\operatorname{Gain}(S, A) & =-2.0518-(113 / 197 *-2.0010)+(38 / 197 *-2.0364)+(46 / 197 *-3.1402) \\
& =-2.03008431
\end{aligned}
$$




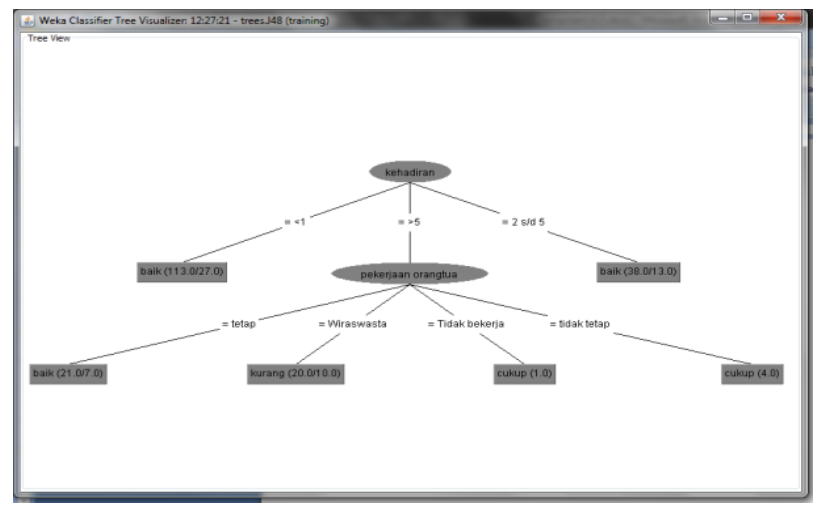

Gambar 1. Gambar Pohon Keputusan dari C4.5

Dari gambar pohon keputusan diatas didapat aturan-aturan sebagai berikut:

1. IF kehadiran $=<1$ : baik AND kehadiran $=>5$ THEN diterima

2. IF pekerjaan orangtua tetap: baik THEN diterima

3. IF pekerjaan orangtua $=$ Wiraswasta: kurang THEN terima

4. IF pekerjaan orangtua $=$ Tidak bekerja: cukup THEN terima

5. IF pekerjaan orangtua $=$ tidak tetap: cukup THEN terima

6. IF kehadiran $=2 \mathrm{~s} / \mathrm{d} 5$ : baik THEN terima

Tabel 2. Hasil dan Nilai Entropy dan Gain untuk menentukan simpul akar dengan data training

\begin{tabular}{|c|c|c|c|c|c|c|}
\hline Simpul & & Kasus & Terima & Tidak & Entropy & Gain \\
\hline \multirow[t]{7}{*}{ Kelas } & & 131 & 57 & 74 & -2.0245 & -3.1023 \\
\hline & $\mathrm{X}-1$ & 19 & 6 & 13 & -2.2105 & \\
\hline & $\mathrm{X}-2$ & 7 & 3 & 4 & -2.0297 & \\
\hline & $\mathrm{X}-3$ & 24 & 8 & 16 & -2.1699 & \\
\hline & XI IPA-1 & 22 & 10 & 12 & -2.0120 & \\
\hline & XI IPA-2 & 36 & 16 & 20 & -2.0179 & \\
\hline & XI IPS & 23 & 8 & 15 & -2.1402 & \\
\hline \multirow[t]{5}{*}{ Pekerjaan orangtua } & & 131 & 57 & 74 & -2.0245 & -1.3984 \\
\hline & wiraswasta & 39 & 18 & 21 & -2.0086 & \\
\hline & tetap & 78 & 24 & 54 & -2.2310 & \\
\hline & tidak tetap & 11 & 8 & 3 & -2.3339 & \\
\hline & tidak bekerja & 3 & 1 & 2 & -2.1699 & \\
\hline \multirow[t]{5}{*}{ Penghasilan orangtua } & & 131 & 57 & 74 & -2.0245 & -2.6255 \\
\hline & $<1000000$ & 53 & 26 & 27 & -2.0005 & \\
\hline & $1050000-2000000$ & 37 & 17 & 20 & -2.0095 & \\
\hline & $>2000000$ & 38 & 7 & 31 & -2.7343 & \\
\hline & tidak ada & 3 & 1 & 2 & -2.1699 & \\
\hline \multirow[t]{4}{*}{ Pengeluaran } & & 131 & 57 & 74 & -2.0245 & -2.4436 \\
\hline & $<1000000$ & 56 & 27 & 29 & -2.0018 & \\
\hline & $1050000-2000000$ & 47 & 17 & 30 & -2.1148 & \\
\hline & $>2000000$ & 28 & 7 & 21 & -2.4150 & \\
\hline
\end{tabular}




\begin{tabular}{|l|l|r|r|r|r|r|}
\hline Simpul & & Kasus & Terima & Tidak & Entropi & Gain \\
\hline Jumlah tanggungan & & 131 & 57 & 74 & -2.0245 & -3.7971 \\
\hline & 1 & 10 & 4 & 6 & -2.0589 & \\
\hline & $2-4$ orang & 101 & 37 & 64 & -2.1070 & \\
\hline & $>4$ & 20 & 10 & 10 & -2.0000 & \\
\hline & & 131 & 57 & 74 & -2.0245 & -1.9300 \\
\hline & $<1$ & 76 & 37 & 39 & -2.0010 & \\
\hline & 2 s/d 5 & 24 & 9 & 15 & -2.0931 & \\
\hline $\begin{array}{l}\text { Kegiatan } \\
\text { pengembadiran }\end{array}$ & $>5$ & 31 & 5 & 26 & -2.8860 & \\
\hline & & 131 & 57 & 74 & -2.0245 & -3.0005 \\
\hline & baik & 89 & 38 & 51 & -2.0311 & \\
\hline & cukup & 29 & 11 & 18 & -2.0866 & \\
\hline & kurang & 13 & 2 & 11 & -2.9414 & \\
\hline
\end{tabular}

Perhitungan entropy dan gain untuk semua atribut dilakukan, untuk mendapatkan nilai gain tertinggi. Hasil perhitungan seluruh atribut terlihat pada Tabel 1.

\section{Perhitungan Naïve Bayes.}

Dengan mencari prior probability untuk nilai yang diterima dan tidak diterima untuk semua jumlah data. Jika diketahui dalam data training, jumlah data 197, siswa yang diterima beasiswa dalam kelas terima 80 record dan yang tidak diterima dalam kelas tidak 119 record.

Tabel 3. Perhitungan probabilitas prior

\begin{tabular}{|c|c|c|c|c|c|}
\hline & & Terima & Tidak & & \\
\hline & & & & & \\
\hline total & & 80 & 117 & 0.1663 & 0.2432 \\
\hline Kelas & & & & 0.0000 & 0.0000 \\
\hline & $\mathrm{X}-1$ & 12 & 24 & 0.0249 & 0.0499 \\
\hline & $\mathrm{X}-2$ & 13 & 22 & 0.0270 & 0.0457 \\
\hline & $X-3$ & 13 & 19 & 0.0270 & 0.0395 \\
\hline & XI IPA-1 & 10 & 12 & 0.0208 & 0.0249 \\
\hline & XI IPA-2 & 16 & 20 & 0.0333 & 0.0416 \\
\hline & XI IPS & 16 & 20 & 0.0333 & 0.0416 \\
\hline Pekerjaan orangtua & & & & 0.0000 & 0.0000 \\
\hline & wiraswasta & 34 & 37 & 0.0707 & 0.0769 \\
\hline & tetap & 35 & 73 & 0.0728 & 0.1518 \\
\hline & tidak tetap & 8 & 5 & 0.0166 & 0.0104 \\
\hline & tidak bekerja & 3 & 2 & 0.0062 & 0.0042 \\
\hline Penghasilan orangtua & & & & 0.0000 & 0.0000 \\
\hline & $<1000000$ & 44 & 44 & 0.0915 & 0.0915 \\
\hline & $1050000-2000000$ & 25 & 24 & 0.0520 & 0.0499 \\
\hline & $>2000000$ & 10 & 47 & 0.0208 & 0.0977 \\
\hline & tidak ada & 1 & 2 & 0.0021 & 0.0042 \\
\hline
\end{tabular}




\begin{tabular}{|c|c|c|c|c|c|}
\hline Pengeluaran & & & & 0.0000 & 0.0000 \\
\hline & $<1000000$ & 45 & 46 & 0.0936 & 0.0956 \\
\hline & $1050000-2000000$ & 26 & 44 & 0.0541 & 0.0915 \\
\hline & $>2000000$ & 9 & 27 & 0.0187 & 0.0561 \\
\hline Jumlah tanggungan & & & & 0.0000 & 0.0000 \\
\hline \multirow[t]{3}{*}{ orangtua } & 1 & 4 & 7 & 0.0083 & 0.0146 \\
\hline & $2-4$ orang & 60 & 93 & 0.1247 & 0.1933 \\
\hline & $>4$ & 16 & 17 & 0.0333 & 0.0353 \\
\hline \multirow[t]{5}{*}{ Ranking } & & & & 0.0000 & 0.0000 \\
\hline & 1 & 8 & 0 & 0.0166 & 0.0000 \\
\hline & $2 \mathrm{~s} / \mathrm{d} 4$ & 17 & 0 & 0.0353 & 0.0000 \\
\hline & $5 \mathrm{~s} / \mathrm{d} 10$ & 41 & 4 & 0.0852 & 0.0083 \\
\hline & tidak ada & 14 & 113 & 0.0291 & 0.2349 \\
\hline \multirow[t]{5}{*}{ Nilai raport } & & & & 0.0000 & 0.0000 \\
\hline & $<60$ & 0 & 0 & 0.0000 & 0.0000 \\
\hline & $61-70$ & 0 & 8 & 0.0000 & 0.0166 \\
\hline & $71-80$ & 38 & 102 & 0.0790 & 0.2121 \\
\hline & $>80$ & 42 & 7 & 0.0873 & 0.0146 \\
\hline \multirow[t]{4}{*}{ Kehadiran } & & & & 0.0000 & 0.0000 \\
\hline & $<1$ & 58 & 55 & 0.1206 & 0.1143 \\
\hline & $2 \mathrm{~s} / \mathrm{d} 5$ & 16 & 22 & 0.0333 & 0.0457 \\
\hline & $>5$ & 6 & 40 & 0.0125 & 0.0832 \\
\hline \multirow[t]{4}{*}{ Kepribadian } & & & & 0.0000 & 0.0000 \\
\hline & baik & 80 & 113 & 0.1663 & 0.2349 \\
\hline & cukup & 0 & 2 & 0.0000 & 0.0042 \\
\hline & kurang & 0 & 2 & 0.0000 & 0.0042 \\
\hline \multirow[t]{4}{*}{$\begin{array}{l}\text { Kegiatan pengembangan } \\
\text { diri }\end{array}$} & & & & 0.0000 & 0.0000 \\
\hline & baik & 57 & 74 & 0.1185 & 0.1538 \\
\hline & cukup & 19 & 24 & 0.0395 & 0.0499 \\
\hline & kurang & 4 & 19 & 0.0083 & 0.0395 \\
\hline
\end{tabular}

Untuk menentukan kasus baru termasuk kelas mana, dilakukan perhitungan probabilitas posterior berdasarkan probabilitas prior probabilitas posterior untuk menentukan data testing termasuk klasifikasi mana terdapat pada Tabel 4. Misalkan diambil sebuah data testing $\mathrm{X}$ dengan nilai seperti pada Tabel 3 kolom dua, untuk menentukan kelas mana, dilakukan perhitungan probabilitas posterior yang hasilnya terdapat pada Tabel 3 kolom tiga dan empat. 
Tabel 4. Perhitungan Probabilitas Posterior

\begin{tabular}{|l|l|r|r|}
\hline \multicolumn{2}{|c|}{ Data X } & \multicolumn{1}{c|}{ P(X) $\left.\mathbf{C}_{\mathbf{i}}\right)$} \\
\hline Kelas & \multicolumn{1}{|c|}{ Nilai } & \multicolumn{1}{c|}{ Terima } & \multicolumn{1}{c|}{ Tidak } \\
\hline Pekerjaan orangtua & \multicolumn{1}{|c|}{ X-1 } & 0.0249 & 0.0499 \\
\hline Penghasilan orangtua & tetap & 0.0728 & 0.1518 \\
\hline Pengeluaran & $1050000-2000000$ & 0.0520 & 0.0499 \\
\hline Jumlah tanggungan orangtua & 2-4 orang & 0.0187 & 0.0561 \\
\hline Ranking & 5 s/d 10 & 0.1247 & 0.1933 \\
\hline & & 0.0852 & 0.0083 \\
\hline Nilai raport & $71-80$ & & \\
\hline Kehadiran & 2 s/d 5 & 0.0790 & 0.2121 \\
\hline Kepribadian & baik & 0.0333 & 0.0457 \\
\hline Kegiatan pengembangan diri & cukup & 0.1663 & 0.2349 \\
\hline
\end{tabular}

Dari hasil perhitungan di atas, didapat nilai $\mathrm{P}\left(\mathrm{X} \mid \mathrm{C}_{\mathrm{i}}\right)$ dan $\mathrm{P}\left(\mathrm{X} \mid \mathrm{C}_{\mathrm{i}}\right) \mathrm{P}\left(\mathrm{C}_{\mathrm{i}}\right)$ lebih besar untuk remark = terima sehingga dapat disimpulkan bahwa data testing tersebut termasuk klasifikasi good.

\section{Neural Network}

Gambar 2 adalah neural net yang dihasilkan dari pengolahan data training dengan metode neural network adalah multilayer perceptron yang dihasilkan dari data training pada Tabel . Terdiri dari tiga layer, yaitu Input layer terdiri dari 21 simpul, sama dengan jumlah atribut prediktor ditambah satu simpul bias. Pada pembahasan ini digunakan satuhidden layer yang terdiri dari 20 simpul diambah satu simpul bias. Di bagian output layer terdapat dua simpul yang mewakili atribut kelas yaitu terima dan tidak.

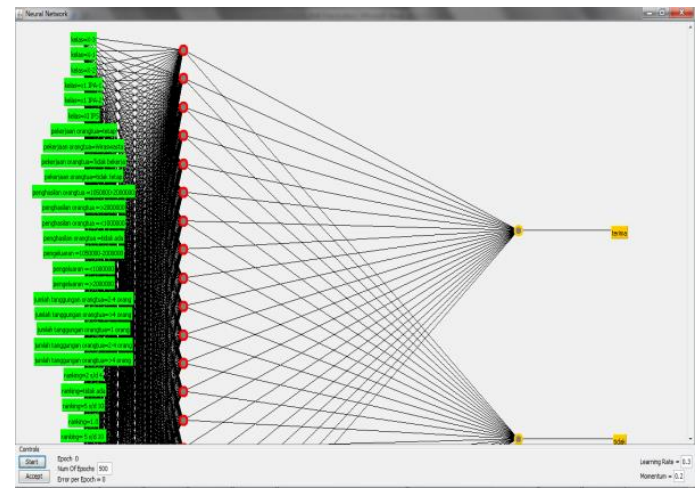

Gambar 2. Neural net

Tabel 5 adalah nilai akhir fungsi aktifasi pada output layer. Kolom pertama pada Tabel 5 menyatakan class, yaitu atribut kelas yang dinyatakan dengan simpul pada output layer seperti pada gambar 2 . 
Tabel 5. Nilai Bobot Akhir untuk Output Layer

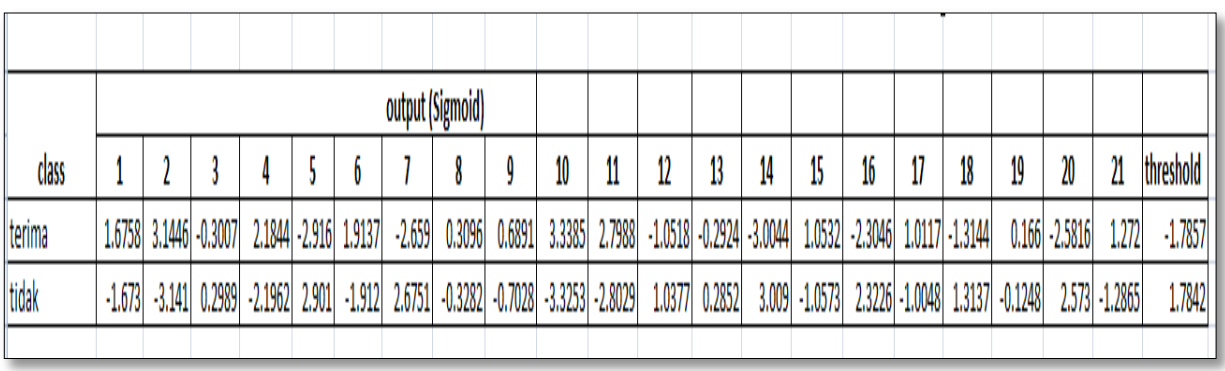

\section{Evaluasi dan Validasi}

\section{Pengujian model}

Model yang telah dibentuk diuji tingkat akurasinya dengan memasukan data uji yang berasal dari data training. Karena data yang didapat dalam penelitian ini setelah proses preprocessing hanya 197 data maka digunakan metode cross validation untuk menguji tingkat akurasi. Untuk nilai akurasi model untuk metode $\mathrm{C} 4.5$ sebesar $67.1642 \%$ metode naïve bayes sebesar $86.5672 \%$, dan metode neural network sebesar $82.0896 \%$.

\section{Confision Matrix}

Tabel 6. Model Confusion Matrix untuk Metode C4.5

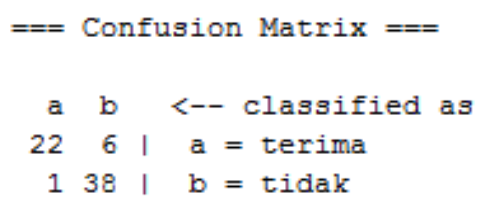

Tabel 7. Model Confusion Matrix untuk Metode Naïve bayes

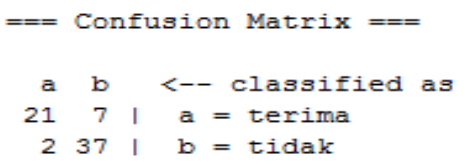

Tabel 8. Model Confusion Matrik Metode Neural Network

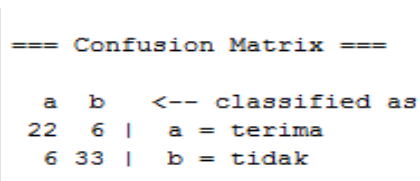

Dari tiga table confusion matrix, selanjutnya dilakukan perhitungan nilai accuracy, precision dan recall. Perbandingan nilai accuracy, precision, dan recall yang telah dihitung untuk metode C4.5, naïve bayes, dan neural network dapat dilihat pada Tabel 9. 
Tabel 9. Komparasi Nilai Accuracy, Precision, dan Recall

\begin{tabular}{lccc} 
& & & \\
& C4.5 & Naive Baves & Neuralnetwork \\
\hline Accuracy & $67.1642 \%$ & $86.5672 \%$ & $82.0896 \%$ \\
Precision & $0.727 \%$ & $0.913 \%$ & $0.786 \%$ \\
Recall & $0.87 \%$ & $0.75 \%$ & $0.786 \%$ \\
\hline
\end{tabular}

\section{Kurva ROC}

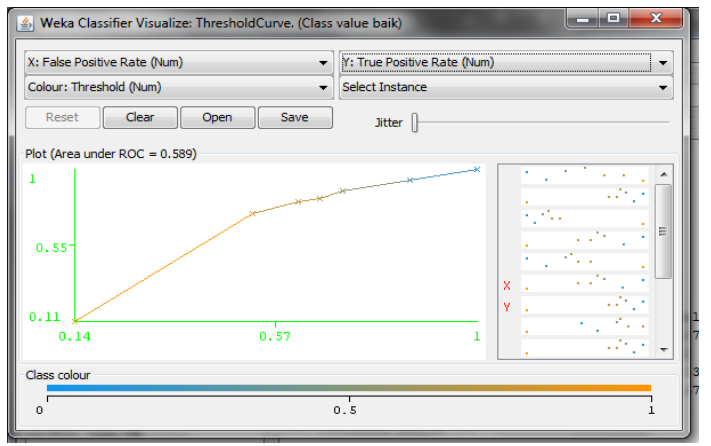

Gambar 3. Kurva ROC Algoritma C4.5

Kurva ROC pada gambar 3 diatas mengekspresikan confusion matrix Garis $\mathrm{X}$ adalah false positives dan garis Y true positives, sebesar 0.589 .

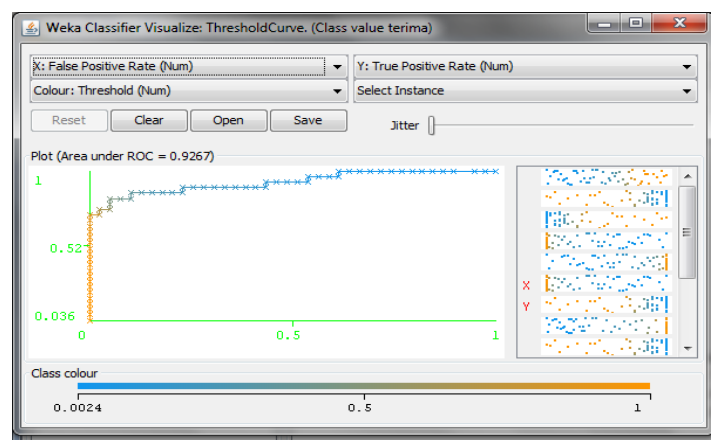

Gambar 4. Kurva ROC Naïve Bayes

Hasil yang didapat dari pengolahan ROC untuk Nä̈ve Bayes sebesar 0.9267 dapat dilihat pada gambar 4 .

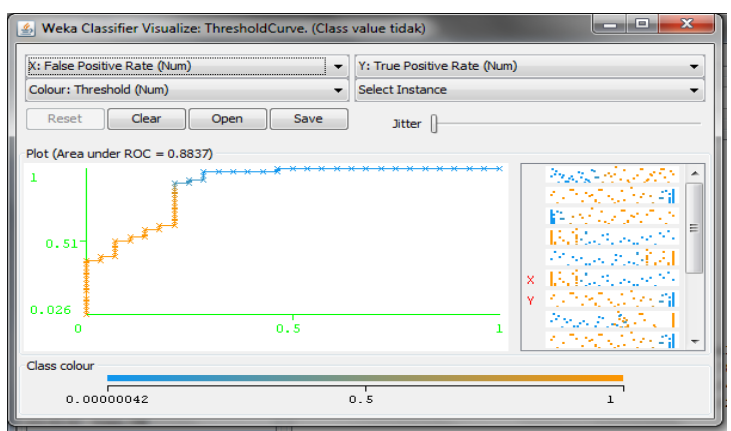

Gambar 5. Kurva ROC Neural Network 
Hasil yang didapat dari pengolahan ROC untuk Neural Network sebesar 0.8837 dapat dilihat pada gambar 5 .

Setelah dilakukan perhitungan pada kurva ROC maka didapatlah hasil perbandingan tersebut. Perbandingan hasil perhitungan nilai AUC untuk metode C4.5, nä̈ve bayes, dan neural network dapat dilihat pada Tabel 10.

Tabel 10. Komparasi Nilai AUC

\begin{tabular}{cccc}
\hline & C4.5 & Naive Baves & Newralnetwork \\
\hline AUC & 0.589 & 0.9267 & 0.8837 \\
\hline
\end{tabular}

\section{Analisis hasil komparasi}

Model yang dihasilkan dengan metode C4.5, naïve bayes, dan neural network diuji menggunakan metode Cross Validation, terlihat perbandingan nilai accuracy, precision, dan recall pada Tabel 11 .

Tabel 11. Komparasi Nilai Accuracy dan AUC

\begin{tabular}{lccc}
\hline & C4.5 & Naive Boves & Neuralnetwork \\
\hline Accuracy & $67.1642 \%$ & $86.5672 \%$ & $82.0896 \%$ \\
AUC & 0.589 & 0.9267 & 0.8837 \\
\hline
\end{tabular}

Tabel 11 membandingkan accuracy dan AUC dari tiap metode. Terlihat bahwa nilai accuracy Naïve Bayes paling tinggi begitu pula dengan nilai AUC-nya. Untuk metode C4.5 dan Neural Network juga menunjukan nilai yang sesuai.

\section{Penerapan Algoritma Terpilih}

Tabel 12. Data Baru untuk Penerapan Algoritma Terpilih

\begin{tabular}{|c|c|c|c|c|c|c|c|c|c|c|}
\hline$x \cdot 1$ & Wiraswasta & $<100000$ & $<1000000$ & 2-4orang & & 1180 & 4 & baik & cukun & terima \\
\hline$x \cdot 1$ & tetap & $>2000000$ & $1050000-200$ & Q2-4orang & tidaka ada & 771-80 & $25 / d 5$ & baik & kurang & tidak \\
\hline$x .2$ & Wiraswasta & 1000000 & $\$ 1000000$ & Xorang & tididakada & 771-80 & $25 / d 5$ & baik & baik & tidak \\
\hline$x-2$ & Wiraswasta & $\$ 1000000$ & $\$ 1000000$ & 2-4 orang & $5 s / d 10$ & 180 & 4 & baik & coukup & terima \\
\hline$x-3$ & tetap & $>2000000$ & $>2000000$ & $2-4$ orang & $5 s / d 10$ & 180 & 4 & baik & baik & terima \\
\hline$x-3$ & tetap & $>2000000$ & $>2000000$ & $2-4$ orang & tidak ada & 771-80 & 15 & baik & baik & tidak \\
\hline XI PA- & Wiraswasta & $\$ 1000000$ & $\leqslant 1000000$ & 2-4orang & $5 s / d 10$ & $\$ 80$ & 4 & baik & baik & terima \\
\hline$x \mid$ XIPA: & Wiraswasta & 4000000 & $\$ 1000000$ & 2-4orang & $5 s / d 10$ & 180 & 4 & baik & baik & terima \\
\hline$X \|$ PS & tidak tetap & $\$ 1000000$ & $\$ 1000000$ & 2-4orang & $5 s / d 10$ & $71 \cdot 80$ & $25 / d 5$ & baik & baik & terima \\
\hline$X \| P S$ & tetap & $>2000000$ & $1050000-2000$ & Q2-4orang & tidak ada & 61.70 & 4 & kurang & baik & tidak \\
\hline
\end{tabular}

Hasil penerapan rule algoritma Naïve Bayes terhadap data baru sejumlah 10 record data dimana 6 data diprediksi terima dan 4 data diprediksi tidak. Dengan tingkat akurasi sebesar 70\%. Dan dapat dilihat juga tabel dari Confusion Matrix pada tabel 13. 
Tabel 13. Confussion Matrix Data Baru dengan Algoritma Nä̈ve Bayes

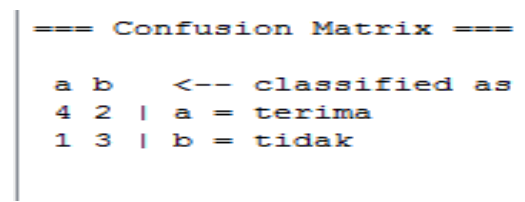

\section{Kesimpulan}

Dalam penelitian ini dilakukan pembuatan model menggunakan algoritma $\mathrm{C} 4.5$, naïve bayes dan neural network menggunakan data siswa yang menerima beasiswa di sekolah. Model yang dihasilkan, dikomparasi untuk mengetahui algoritma yang paling baik dalam pemilihan penerima beasiswa. Untuk mengukur kinerja ketiga algoritma tersebut digunakan metode pengujian Confusion Matrix dan Kurva ROC, diketahui bahwa algoritma Naïve Bayes memiliki nilai accuracy dan AUC paling tinggi.

Dengan demikian algoritma Naïve Bayes merupakan algoritma terbaik dan dapat memberikan pemecahan dalam permasalahan pemilihan penerima beasiswa di sekolah.

\section{Saran}

1. Hasil penelitian ini diharapkan bisa digunakan pada sekolah, untuk lebih meningkatkan akurasi analisa penerima beasiswa bagi siswa.

2. Untuk mendukung pengambilan keputusan dan pengembangan system informasi manajemen strategik, model ini dapat diterapkan pada sekolah dengan menerapkan system yang menggunakan perangkat keras dan perangkat lunak, disertai dengan pembuatan Standard Operational Procedure dan pelatihan bagi end-user.

\section{Daftar Pustaka}

Alpayadin, E. (2010). Introduction to Machine Learning. London: The MIT Press.

Anneahira. (2012). Tujuan Beasiswa Dalam

http://www.anneahira.com/beasiswa.htm(diakses pada tanggal 3 Juni 2012).

Kusrini, dan Luthfi, Emha Taufik. (2009). Algoritma Data Mining. Edisi I. Yogyakarta:Andi Publishing.

Larose, Daniel. T. (2005). Discovering Knowledge in Data. New Jersey: John Willey \& Sons, Inc. 